\title{
Note on Hungarian Pronunciation
}

All Hungarian names and words are pronounced with a strong accent on the first syllable. The Hungarian $s z$ is equivalent in sound to the English $s$ in soft; this is distinct from the $z s$, which sounds like the $s$ in measure. The Hungarian $s$ sounds like the English sh (as in shout). The letter $j$ and the clusters $l y$ and $l j$ all approximate the English $y$ (as in you); the cs sounds like the English $c h$ in much. The cluster $g y$ resembles the $d$ in the British pronunciation of duke; the $t y$, analogously, sounds like the $t$ in the British tube.

As for vowel sounds, the Hungarian $a$ is somewhat darker than the English, as in father rather than yam; the á, by contrast, is bright and forward, as in cat. When written with an acute accent, the unmarked $o$ as in moth becomes the long $o$ as in soap. Otherwise, the acute accent primarily affects the length of the syllable rather than the sound. The Hungarian $i$ sounds like the English long ee ( $f e e$ ), the Hungarian $e$ like the English ay (pay), and the Hungarian $u$ like the English oo (or the $u$ in rule); all are clipped when spelled without the accent mark and elongated with it. The vowels ó and $\ddot{u}$ are elongated equivalents of the shorter $\ddot{o}$ and $\ddot{u}$, which are pronounced as they are in German.

Thus, in approximate transliteration:

$\begin{array}{ll}\text { Bartók } & \begin{array}{l}\text { BAR-toak (with the oa long, as in soap) } \\ \text { Kadosa }\end{array} \\ \text { KAHonczy } & \begin{array}{l}\text { LO-shon-see (with both o's dark and short, as in } \\ \text { moth) }\end{array} \\ \text { Lukács } & \text { LOO-kach (with the } a \text { bright and elongated) } \\ \text { Mihály } & \text { MEE-high (the forward } a \text { blends with the cluster } l y \text { ) } \\ \text { Nagy } & \text { NODGE }\end{array}$


$\mathrm{xx} \quad / \quad$ Note on Hungarian Pronunciation

Rákosi

RA-ko-shee (with the $a$ forward, as in cat, and elongated)

Révai RAY-vaw-yee

Szabó SOB-oh

Székely SAY-kay

Széll SAIL

Szervánszky SER-van-skee (with bright, forward, somewhat elongated $a$ ) 